\title{
The Effect of Loneliness in Psychological and Behavioral Profile among High School Students in Spain
}

\author{
Alexandra Martín-Rodríguez ${ }^{1}\left(\mathbb{D}\right.$, Jose Francisco Tornero-Aguilera ${ }^{1}{ }^{\circledR}$, Pedro Javier López-Pérez ${ }^{2}$ \\ and Vicente Javier Clemente-Suárez ${ }^{1,3, *(D)}$ \\ 1 Faculty of Sports Sciences, Universidad Europea de Madrid, Tajo Street, s/n, 28670 Madrid, Spain; \\ sandra.martin.rodriguez8@gmail.com (A.M.-R.); Josefrancisco.tornero@universidadeuropea.es (J.F.T.-A.) \\ 2 Facultad de Ciencias Sociales y Humanas, Universidad de la Costa, Barranquilla 080002, Colombia; \\ plopez10@cuc.edu.co \\ 3 Grupo de Investigación en Cultura, Educación y Sociedad, Universidad de la Costa \\ Barranquilla 080002, Colombia \\ * Correspondence: vctxente@yahoo.es; Tel.: +34-902-232-350; Fax: +34-911-413-585
}

Citation: Martín-Rodríguez, A.; Tornero-Aguilera, J.F.; López-Pérez, P.J.; Clemente-Suárez, V.J. The Effect of Loneliness in Psychological and Behavioral Profile among High School Students in Spain. Sustainability 2022, 14, 168. https:/ / doi.org/10.3390/su14010168

Academic Editor: Hyo Sun Jung

Received: 8 November 2021

Accepted: 23 December 2021

Published: 24 December 2021

Publisher's Note: MDPI stays neutral with regard to jurisdictional claims in published maps and institutional affiliations.

Copyright: (C) 2021 by the authors. Licensee MDPI, Basel, Switzerland. This article is an open access article distributed under the terms and conditions of the Creative Commons Attribution (CC BY) license (https:// creativecommons.org/licenses/by/ $4.0 /)$.

\begin{abstract}
Loneliness is a distressing feeling that can be a barrier to a student's development and affect their mental health. This research aimed to analyse the effects of loneliness on psychological and behavioral factors among students aged 12-19 years in Spain. Loneliness, experiential avoidance, psychological inflexibility, physical activity, mobile phone use, and smoke habits were analysed in a sample of 110 men and 122 women assigned into two groups depending on their loneliness levels: higher loneliness group (HLG) and lower loneliness group (LLG). Results showed that experimental avoidance and psychological inflexibility were related with loneliness $(r=0.471 ; p=0.000)$. Experiential avoidance and psychological inflexibility were higher in HLG than LLG. Regarding the use of mobile phones and smoking habits, LLG presented significantly higher values than HLG. Higher age correlated with lower loneliness values $(r=-0.155 ; p=0.017)$. The present research found how students with higher loneliness presented higher experiential avoidance and psychological inflexibility and lower age, use of mobile phone, and smoking habits. These findings reveal the importance of considering multiple social behaviours when examining adolescent mental health factors.
\end{abstract}

Keywords: loneliness; physical activity; psychological inflexibility; adolescence; experiential avoidance

\section{Introduction}

Loneliness is considered as the stressful situation that happens when a person's social relationships are perceived to be less than needed or expected. In other words, humans, as a social specie, need a sense of belonging [1]. It is associated with negative outcomes across different age groups including adolescents. In this sense, it is becoming an increasing problem that involves health issues associated with the risk of diverse emotional, social, and behavioural diseases [2]. Moreover, the current COVID-19 pandemic and regional lockdowns have raised this painful experience among the youth [3].

Adolescence is the phase of life between childhood and adulthood, from ages 10 to 19 . It is a unique stage of human development and an important time for laying the foundations of good health [4]. It is a transitional stage of physical and psychological development that generally occurs during the period from puberty to legal adulthood. It is known that this period is also a time where lifestyle behaviours can constantly impact on long-term health. This lifestyle could be influenced by physical and psychological changes depending on how the presence of important family members or friends is perceived by them [5]. More precisely, this phase of growth implies a time where a feeling of loneliness could play a crucial and irreversible role in their development. From a cognitive standpoint, it is needed to highlight several disorders suffered by adolescents who are feeling lonely without any kind of backing [5]. This could be attributed to the next internal components. 
Firstly, behavioural inhibition is an important risk factor for the development of pathological anxiety in youths [6]. Adolescents tend to be more susceptible to feeling more anxious and impatient if they perceive a poor support system around them [7]. As mentioned above, feelings of loneliness motivate people to build a connection or reconnection with others, thereby abolishing social isolation. Furthermore, this maintenance could not be formed with a proper cognitive factor-like decision making and attention, which are affected by loneliness [8]. Moreover, in this period the loss of self-confidence and being worried for their own future is also remarkable. Additionally, several studies point out that they likely could have some difficulties concentrating, maintaining focus, and reducing memory capability. Poor relations with parents and negative peer experiences such as lack of social acceptance and victimization could be the point of connection of all these emotional difficulties and, then, feelings of loneliness. [9].

Consequently, the importance of developing social competence and the capacity to engage effectively in a social relationship is essential in their evolution. As a result, chronic isolation has been recognized as a risk factor for drunkenness and cigarette use [10], both disruptive behaviours that increase mortality and increase the risk to suffer other complex diseases and disorders [11]. As a response to this complex situation, physical activity offers a new opportunity to control these emotional reactions. In this way, the positive effect of physical activity on mental health and cognitive performance has been proved. In this line, it was found how physically inactive adolescents and those who do not participate in physical education classes were more likely to feel lonely [12].

Loneliness has been studied in different situations and different kind of growth phases. It is a complex construct that includes three related dimensions: (1) intimate loneliness; (2) relational loneliness, and (3) collective loneliness [13]. The first one refers to the perceived absence of a significant someone, the second one relates to the presence/absence of quality friendships, and the last one applies to a person's valued social identities or "active network". Studies have shown how loneliness is a risk factor for cognitive decline and the progression of Alzheimer's Disease [14], recurrent strokes and obesity [15], increased vascular resistance and elevated blood pressure [16], increased hypothalamic-pituitaryadrenocortical activity [17], decreased sleep salubrity [18], amongst others. Focusing on adolescents' lifestyle and education, which is a multifactorial phenomenon subject to a different level of social pressure, it could be observed how the subjects with high loneliness presented a greater probability to suffer some health issues linked to risk of diverse emotional, social, and behavioural diseases.

Regarding the experience of loneliness among students aged 12-19 years, it was proved that self-reported loneliness is associated with poorer health and a less positive perception of health status [19-21]. In this line, loneliness could modify some students' behaviours and it is related to more frequent use of medical services among youth as well as sleep problems [19]. Given the importance of good sleep for life quality and academic achievement [22], these sleep problems should be taken into account. Sleep provides restorative effects for ensuring good health; however, less efficient sleep could affect brain development, including memory development, executive functioning, and cognitive performance $[23,24]$. For these reasons and in line with our study, further examinations are needed to understand how loneliness affects adolescents' life. From a practice point of view, it is crucial to develop interventions and health-education efforts to fight it among youth. Findings also suggest that an effective programme aimed at preventing loneliness may also have more general positive implications for adolescents' well-being.

The objective of the present research was to analyse the effects of loneliness on the psychological and behavioural factors among students aged 12-19 years. The initial hypothesis was that students with higher levels of loneliness would present higher experiential avoidance and psychological inflexibility and disruptive behaviours. 


\section{Materials and Methods}

\subsection{Participants}

We studied 232 adolescents and young adult students. Participants were between 12 and 19 years old $(M=16.1 \pm 1.3)$. Among them, 110 were men and 122 were women. All of them filled in an informed consent form, and when they were under 18 years old a written parental consent was obtained in accordance with the Helsinki Declaration guidelines. All the data were collected via an online questionnaire in a period of one month in December 2020. The study was approved by the university ethics committee (CIPI/18/074), the direction of the educational centre, and the parents' association.

\subsection{Instruments}

To achieve the research aims, students completed a battery of questionnaires. Students completed the questionnaires by an online service, at one time, in their homes, in lecture time (09:00 to 14:00) using their personal computers. The questionaries were the following.

Psychological profile: The Spanish version of the UCLA Loneliness Scale $[25,26]$ was used to scale measure loneliness (Cronbach's alpha $=0.89$; average inter-item correlation $=0.72$ ). In the present study, we used a condensed version, which consists of three items answered by a 3-point Likert scale score, where 1 means never and 3 means frequently. The scores for each item were added up to produce a loneliness scale from 3 to 9 , with higher scores indicating a greater degree of loneliness. The cut-off point for loneliness groups was $\geq 6$, in line with previous studies [27].

The Spanish version of the Acceptance and Action Questionnaire II [28,29] was used to analyse the experiential avoidance or psychological inflexibility through seven items answered by a 7-point Likert scale, where 0 means never true and 7 means always true.

Physical activity was counted by the number of hours per week. This variable was analysed by a questionnaire used by previous authors, which includes the following items: "How many hours are you physically active, in movement, per day?"; "Do you practice any endurance-based exercise (swimming, cycling, running, etc.)? If yes, how long do you train per week?"; "Do you practice any sport team-related exercise (football, rugby, hockey, etc.)? If yes, how long do you train per week?" "Do you practice any strengthbased sport (weights, CrossFit, Calisthenics, etc.). If yes, how long do you train per week?". Questions should be answered by choosing the option offered that fits the best with the physical activity developed by the subject. According to the first question, "How many hours are you active, in movement, per day?" answers ranged from "less than 30 min" to "more than three hours". In the case of the rest of the questions, the answers range from "I do not practice this kind of training" to "more than $12 \mathrm{~h}$ ".

Use of mobile phone: Based on self-report. It was counted by the number of hours of mobile phone use per day.

Smoke habits: Based on self-report. It was counted by the number of cigarettes smoked per day.

Sleep habits: Based on self-report. It was counted by the number of hours of sleep per day.

\subsection{Procedure}

The week before data collection, researchers visited each school to introduce themselves to the adolescents and to show the devices used for the data collection to familiarize them with every procedure. The data collection took place in December 2020 and the call to participate in the study was made through a link sent by researchers.

Students were classified into two analysis groups, LLG: students that presented the low values in the UCLA Loneliness Scale (3.0 \pm 0.0$)$, and HLG: students that presented and higher values in the UCLA Loneliness Scale $(5.5 \pm 1.7)$. The cut-off point was $\geq 3$. 


\subsection{Statistical Analysis}

Statistical analysis was carried out using the Statistical Package for the Social Sciences (SPSS) version 22.0 for Windows (IBM: Armonk, NY, USA). Descriptive statistics (mean and standard deviation) were analysed for each variable. Kolmogorov-Smirnov test was used to test the normality of the sample. As all the parameters presented a parametric distribution a Multivariate Analysis of the Variance (MANOVA) with loneliness as a fixed factor was conducted to test differences in the study variables by this factor. In addition, a bivariate correlational analysis by the Pearson test was conducted. The level of significance for all the comparisons was set at $p \leq 0.05$.

\section{Results}

By the end of the study, 255 students $(81.7 \%)$ have responded to the questionnaires. From the original sample of 312 participants, 232 usable questionnaires were received (74.4\%). The rest of the questionnaires were removed as unusable. We found no significant differences in the number of male and female participants between the two groups analysed. Significantly higher age was found in LLG than in HLG. Additionally, significance was achieved concerning the AAQ scores and loneliness, it is observed that experiential avoidance and psychological inflexibility levels are higher in HLG than in LLG (Table 1). With regards to the usage of mobile phones and smoking habits, LLG presented significantly higher values than HLG.

Table 1. This table shows the differences between high and low loneliness groups in the study variables.

\begin{tabular}{|c|c|c|c|c|c|}
\hline & & Mean \pm SD & F & $p$ & $\eta^{2}$ \\
\hline Age (years) & $\begin{array}{l}\text { LLG } \\
\text { HLG }\end{array}$ & $\begin{array}{c}17.1 \pm 1.45 \\
16.24 \pm 1.33\end{array}$ & 0.422 & $0.017^{*}$ & 0.002 \\
\hline Height $(\mathrm{cm})$ & $\begin{array}{l}\text { LLG } \\
\text { HLG }\end{array}$ & $\begin{array}{c}164.41 \pm 18.11 \\
168.45 \pm 9.23\end{array}$ & 1.422 & 0.235 & 0.009 \\
\hline Weight $(\mathrm{kg})$ & $\begin{array}{l}\text { LLG } \\
\text { HLG }\end{array}$ & $\begin{array}{l}63.14 \pm 13.88 \\
60.29 \pm 10.25\end{array}$ & 1.731 & 0.190 & 0.008 \\
\hline Body mass index $\left(\mathrm{kg} / \mathrm{m}^{2}\right)$ & $\begin{array}{l}\text { LLG } \\
\text { HLG }\end{array}$ & $\begin{array}{c}23.58 \pm 16.35 \\
21.33 \pm 3.11\end{array}$ & 1.445 & 0.232 & 0.008 \\
\hline Acceptance and Action questionnaire-II & $\begin{array}{l}\text { LLG } \\
\text { HLG }\end{array}$ & $\begin{array}{l}15.78 \pm 7.86 \\
23.94 \pm 9.86\end{array}$ & 44.054 & $0.000 * *$ & 0.169 \\
\hline Daily physical activity (h/week) & $\begin{array}{l}\text { LLG } \\
\text { HLG }\end{array}$ & $\begin{array}{l}3.34 \pm 1.28 \\
3.04 \pm 1.21\end{array}$ & 2.816 & 0.095 & 0.013 \\
\hline Aerobic based physical activities (h/week) & $\begin{array}{l}\text { LLG } \\
\text { HLG }\end{array}$ & $\begin{array}{l}1.63 \pm 1.06 \\
1.73 \pm 1.00\end{array}$ & 0.493 & 0.483 & 0.002 \\
\hline Collective based physical activities (h/week) & $\begin{array}{l}\text { LLG } \\
\text { HLG }\end{array}$ & $\begin{array}{l}1.57 \pm 1.00 \\
1.87 \pm 1.31\end{array}$ & 3.446 & 0.065 & 0.016 \\
\hline Performing strength-based physical activities (h/week) & $\begin{array}{l}\text { LLG } \\
\text { HLG }\end{array}$ & $\begin{array}{l}1.55 \pm 0.94 \\
1.49 \pm 1.01\end{array}$ & 0.176 & 0.675 & 0.001 \\
\hline UCLA Loneliness Scale & $\begin{array}{l}\text { LLG } \\
\text { HLG }\end{array}$ & $\begin{array}{c}3 \pm 0.00 \\
5.52 \pm 1.71\end{array}$ & 312.659 & $0.000 * *$ & 0.591 \\
\hline Sleep (h/day) & $\begin{array}{l}\text { LLG } \\
\text { HLG }\end{array}$ & $\begin{array}{c}7.6 \pm 0.83 \\
7.71 \pm 1.06\end{array}$ & 0.822 & 0.366 & 0.004 \\
\hline Mobile phone use (h/day) & $\begin{array}{l}\text { LLG } \\
\text { HLG }\end{array}$ & $\begin{array}{l}4.98 \pm 3.37 \\
3.6 \pm 2.04\end{array}$ & 10.347 & $0.001 * *$ & 0.046 \\
\hline Smoke & $\begin{array}{l}\text { LLG } \\
\text { HLG }\end{array}$ & $\begin{array}{l}1.31 \pm 0.77 \\
1.06 \pm 0.41\end{array}$ & 6.618 & 0.011 * & 0.030 \\
\hline
\end{tabular}

(HLG) High loneliness group; (LLG): Low loneliness group; Statistically significant association between variables at the level ${ }^{*} p<0.05 .{ }^{* *} p<0.01$.

In the correlational analysis we found a significant positive correlation between loneliness and experiential avoidance and psychological inflexibility $(\mathrm{r}=0.471 ; p=0.000)$. In contrast, a negative significant correlation was found between loneliness and age 
$(\mathrm{r}=-0.155 ; p=0.017)$, mobile phone use habit $(\mathrm{r}=-0.219 ; p=0.001)$ and smoking habit $(\mathrm{r}=-0.138 ; p=0.038)$. No significant correlational differences were found between loneliness and the rest of variables measured.

\section{Discussion}

This study aimed to analyse the effects of loneliness on psychological and behavioural factors in adolescent students. The initial hypothesis was partially confirmed since participants with higher levels of loneliness presented higher levels of experiential avoidance and psychological inflexibility but no disruptive behaviours.

We found that HLG presented higher levels of experiential avoidance and psychological inflexibility, this result being in consonance with previous researchers. In this line, the worst states of health have been related to less contextual adaptability [30]. In the case of the present research, we found that psychological inflexibility levels in adolescents were in line with the higher loneliness feelings. As previous studies postulated, this fact could be linked to the current COVID pandemic and the lockdown due to the quarantine, facts that may affect the adolescent psychological health [31]. Social distancing and school closures may, therefore, increase mental health problems in children and adolescents, already at higher risk of developing mental health problems such as depression and anxiety [32]. Focusing on gender and loneliness, previous studies found contradictory results. Moreover, it is important to mention that previous results support the view that women are more willing to admit their loneliness than men [33,34], however, we found no significant differences between genders.

Attending to the dimensions of loneliness concerning behavioural consequences, loneliness was also associated with sleep inadequacy and dissatisfaction, however, our study and previous researchers [35] found no significant association between loneliness and irregular sleep patterns. In this regard, the results obtained in the present study could be due to the peculiarities of the outbreak of the COVID-19 pandemic, even so, the authors found a connection between them [36]. Loneliness has been associated with poorer self-reported sleep quality and daytime sleepiness among adolescents [37]. Thus, knowing that sleep loss could damage or reduce brain development and cognitive performance, the feeling of loneliness should take into account to improve adolescents' academic performance [38]. Future studies may address this issue since, in times of crisis, the manifestations of psychological suffering may be more discreet in adolescents: sleep disturbances, problems with peers, isolation, and depression [39].

Related to the participant's age, lower age was found in HLG. These findings may support the idea that older adolescents may be particularly interested in discovering new social possibilities such as social networks, which could increase their sense of belonging. Accordingly, smartphone use may differ within some of those age groups, especially among younger people [40]. This fact may show us the importance of virtual interaction possibilities with the mobile phone device.

Regarding the behavioural habits of the participants as smoking and mobile phone use, LLG adolescents presented higher values in these variables than HLG. Firstly, mobile phones are becoming an important part of youth culture and one of the most used ways for online communication. In fact, children and adolescents who self-identified as lonely children and adolescents value the Internet as a safer communicative "protected" environment than offline [41]. In this line, technologies may play an important role in the self-esteem of adolescents. Probably, our results may describe a situation where younger adolescents may have a poorer adaptive response to the confinement situation and perceive their mobile phones as their only way out. The access to social media of this collective was described as important for them since without this connection they would miss out and stand out in school as different [42]. Then, social media are potentially a new dimension to consider in this population. Specifically, attending to the loneliness dimensions, human need connectivity, and its potential benefits to reduce isolation, improve social skills and provide a platform for continued communication has been already reported [42]. 
Apparently, due to the perception that confinement may adversely affect their relationships, younger adolescents could consider and perceive the problem more direct and real than older ones. Additionally, as mentioned previously, this absence of social contact with peers due to the confinement situation could lead to an increase in technology consumption. On the other hand, this consumption could be increased by a fully remote learning plan. In both cases, parental monitoring may play a crucial role in confinement so it is needed to expand this work to understand other variables that may be influencing the factors studied.

Smoking is having been recognized as a social habit that improves motivational processes, social acceptance, and belonging. In this line, the desire for social connection can drive excluded and lonely people to engage in smoking, especially when smoking may be linked to the prospect of acceptance. There was converging evidence provided that feelings of social exclusion can be considered a small, but reliable, risk factor for higher rates of smoking, and this effect is strongest among people living in environments in which smoking is socially acceptable [43]. Probably, also their family context could explain and be connected with higher values found in LLG. Parental smoking may have a direct effect on their children's behaviour, added with feeling lonely and misunderstood may push them to this habit. In this context, it should not be forgotten that, although the present research opens up opportunities to further explore other significant variables, parental health habits, economic status, and education level are needed to design social and educational strategies that allow sufficient health measures.

According to physical activity habits, no significant differences between groups were found. In this sense, and linked to our data, it has been confirmed that physical activity levels decrease with age, especially during adolescence. Findings show us a visible decrease between the ages of 11 and 14 years old [44], this global situation may explain our nonsignificant results. Although additional research is needed to explore this possibility, loneliness is accompanied by lower levels of physical performance [45], also the negative emotions associated with confinement and the lack of school-based sport routines could affect them the most. Our findings suggest that there is no doubt that due to lockdown caused by the current pandemic, we are detecting changes in the adolescents' lifestyle where the prevalence of sedentary practices is increasing. For this reason, and knowing the importance of physical activity to the maintenance of health and fitness, it would also be interesting to examine factors that influence social behaviours related to healthy habits, negative emotions as loneliness in current adolescents, focusing specifically, as previously said, on family, friends, and classmates [46-48].

Firstly, loneliness and other variables are self-reported so there is still a chance of an information bias. The validity of answers is a general problem of online surveys. The severe lockdown measures, such as social distancing have hindered physical practice procedures. Additionally, economic status was not included in questionnaires and could be considered an important issue to consider in future research as previous authors highlighted [49], as well as other contextual and behavioural factors such as nutritional, odontological, and psychological patterns that could modulate the contextual profile of adolescents [50-55].

\section{Practical Applications}

Knowing that loneliness could modify and disrupt adolescents' wellness, this research plays an important role in developing practical applications focused on how to prevent and reduce it. Additionally, future researchers may try to understand the students' psychophysiological modifications to improve teaching processes during their academic life. From this point, knowing that psychological variables have an important influence on physiological response results, this research could improve the students' strategies to deal with their social contexts and environments that are highly fluctuating. The knowledge that loneliness perception increases the risk of developing burnout in adolescents [45] and suicidal conduct [46] highlight the importance of applying working dynamics that improve their self-esteem, their feeling of belonging and enhance their sense of autonomy, as well as motivate them to create new social relationships. 


\section{Conclusions}

Students with higher levels of loneliness presented higher levels of experiential avoidance and psychological inflexibility and lower age, use of mobile phones, and smoking habits. These findings reveal the importance of considering multiple social behaviours when examining adolescent mental health factors.

Author Contributions: Conceptualization, V.J.C.-S.; methodology and formal analysis, V.J.C.-S. and P.J.L.-P.; investigation, V.J.C.-S., A.M.-R. and J.F.T.-A.; data curation, V.J.C.-S.; writing-Review and editing, all authors; visualization, all authors; supervision and funding acquisition, V.J.C.-S. All authors have read and agreed to the published version of the manuscript.

Funding: This research received no external funding.

Institutional Review Board Statement: The study was conducted according to the guidelines of the Declaration of Helsinki, and approved by the European University Ethics Committee (CIPI/18/074).

Informed Consent Statement: Consent was obtained from all subjects involved in the study.

Data Availability Statement: All data are presented in the manuscript.

Acknowledgments: We want to acknowledge the collaboration of students, families, and teachers.

Conflicts of Interest: The authors declare no conflict of interest.

\section{References}

1. Hagerty, B.M.; Williams, R.A. The effects of sense of belonging, social support, conflict, and loneliness on depression. Nurs. Res. 1999, 48, 215-219. [CrossRef]

2. Wang, J.; Mann, F.; Lloyd-Evans, B.; Ma, R.; Johnson, S. Associations between loneliness and perceived social support and outcomes of mental health problems. A systematic review. BMC Psychiatry 2018, 18, 156. [CrossRef]

3. Shute, R.H.; Walsh, C. Adolescents with chronic illnesses: School absenteeism, perceived peer aggression, and loneliness. Sci. World J. 2005, 5, 535-544. [CrossRef] [PubMed]

4. WHO. Adolescent Health. Available online: https://www.who.int/health-topics/adolescent-health\#tab=tab_1 (accessed on 19 December 2021).

5. Goosby, B.J.; Bellatorre, A.; Walsemann, K.M.; Cheadle, J.E. Adolescent Loneliness and Health in Early Adulthood. Soc. Inq. 2013, 83, 505-536. [CrossRef] [PubMed]

6. Muris, P.; van Brakel, A.M.; Arntz, A.; Schouten, E. Behavioral inhibition as a risk factor for the development of childhood anxiety disorders: A longitudinal study. J. Child Fam. Stud. 2011, 20, 157-170. [CrossRef]

7. Bangee, M.; Harris, R.A.; Bridges, N.; Rotenberg, K.J.; Qualter, P. Loneliness and attention to social threat in adults: Findings from an eye-tracker study. Personal. Individ. Differ. 2014, 63, 16-23. [CrossRef]

8. Loades, M.E.; Chatburn, E.; Higson-Sweeney, N.; Reynolds, S.; Shafran, R.; Brigden, A.; Linney, C.; McManus, M.N.; Borwick, C.; Crawley, E. Rapid Systematic Review: The Impact of Social Isolation and Loneliness on the Mental Health of Children and Adolescents in the Context of COVID-19. J. Am. Acad. Child Adolesc Psychiatry 2020, 59, 1218-1239. [CrossRef] [PubMed]

9. Krause-Parello, C.A. Loneliness in the school setting. J. Sch. Nurs. 2008, 24, 66-70. [CrossRef]

10. Niño, M.D.; Cai, T.; Ignatow, G. Social isolation, drunkenness, and cigarette use among adolescents. Addict. Behav. 2016, 53, 94-100. [CrossRef]

11. Ezzati, M.; Lopez, A.D.; Rodgers, A.; Vander Hoorn, S.; Murray, C.J.; Comparative Risk Assessment Collaborating Group. Selected major risk factors and global and regional burden of disease. Lancet 2002, 360, 1347-1360. [CrossRef]

12. Madsen, K.R.; Holstein, B.E.; Damsgaard, M.T.; Rayce, S.B.; Jespersen, L.N.; Due, P. Trends in social inequality in loneliness among adolescents 1991-2014. J. Public Health 2019, 41, e133-e140. [CrossRef] [PubMed]

13. Pinto, A.A.; Oppong Asante, K.; Puga Barbosa, R.; Nahas, M.V.; Dias, D.T.; Pelegrini, A. Association between loneliness, physical activity, and participation in physical education among adolescents in Amazonas, Brazil. J. Health Psychol. 2019, 26, 1359105319833741. [CrossRef]

14. Wilson, R.S.; Krueger, K.R.; Arnold, S.E.; Schneider, J.A.; Kelly, J.F.; Barnes, L.L.; Tang, Y.; Bennett, D.A. Loneliness and risk of Alzheimer disease. Arch. Gen. Psychiatry 2007, 64, 234-240. [CrossRef]

15. Cacioppo, J.T.; Hawkley, L.C.; Crawford, E.; Ernst, J.M.; Burleson, M.H.; Kowalewski, R.B.; Malarkey, W.B.; Van Cauter, E.; Bernston, G.G. Loneliness and Health: Potential Mechanisms. Psychosom. Med. 2002, 64, 407-417. [CrossRef]

16. Cacioppo, S.; Grippo, A.J.; London, S.; Goossens, L.; Cacioppo, J.T. Loneliness: Clinical import and interventions. Perspect. Psychol. Sci. 2015, 10, 238-249. [CrossRef]

17. Adam, E.K.; Hawkley, L.C.; Kudielka, B.M.; Cacioppo, J.T. Day-today dynamics of experience-cortisol associations in a population based sample of older adults. Proc. Natl. Acad. Sci. USA 2006, 103, 17058-17063. [CrossRef] 
18. Cacioppo, J.T.; Hawkley, L.C.; Berntson, G.G.; Ernst, J.M.; Gibbs, A.C.; Stickgold, R.; Hobson, J.A. Do lonely days invade the nights? Potential social modulation of sleep efficiency. Psychol. Sci. 2002, 13, 384-387. [CrossRef] [PubMed]

19. Eccles, A.M.; Qualter, P.; Madsen, K.R.; Holstein, B.E. Loneliness in the lives of Danish adolescents: Associations with health and sleep. Scand. J. Public Health 2020, 48, 877-887. [CrossRef] [PubMed]

20. Stickley, A.; Koyanagi, A.; Koposov, R. Loneliness and its association with psychological and somatic health problems among Czech Russia and US adolescents. BMC Psychiatry 2016, 16, 128. [CrossRef] [PubMed]

21. Harris, R.A.; Qualter, P.; Robinson, S.J. Loneliness trajectories from middle childhood to pre-adolescence: Impact of perceived health and sleep disturbance. J. Adolesc. 2013, 36, 1295-1304. [CrossRef]

22. Ejan, J.; Reiter, R.J.; Bax, M.C. Long-term sleep-disturbances in children: A cause of neuronal loss. Eur. J. Paediatr. Neurol. 2010, 14, 380-390.

23. Tarokh, L.; Saletin, J.M.; Carskadon, M.A. Sleep in adolescence:physiology, cognition and mental health. Neurosci. Biobehav. Rev. 2016, 70, 182-188. [CrossRef] [PubMed]

24. Shochat, T.; Cohen-Zion, M.; Tzischinsky, O. Functional consequences of inadequate sleep in adolescents: A systematic review. Sleep Med. Rev. 2014, 18, 75-87. [CrossRef] [PubMed]

25. Hughes, M.E.; Waite, L.J.; Hawkley, L.C.; Cacioppo, J.T. A Short Scale for Measuring Loneliness in Large Surveys: Results from Two Population-Based Studies. Res. Aging 2004, 26, 655-672. [CrossRef]

26. Rodriguez-Besteiro, S.; Tornero-Aguilera, J.F.; Fernández-Lucas, J.; Clemente-Suárez, V.J. Gender differences in the COVID-19 pandemic risk perception, psychology and behaviors of spanish university students. Int. J. Environ. Res. Public Health 2021, 18, 3908. [CrossRef]

27. Steptoe, A.; Shankar, A.; Demakakos, P.; Wardle, J. Social isolation, loneliness, and all-cause mortality in older men and women. Proc. Natl. Acad. Sci. USA 2013, 110, 5797-5801. [CrossRef] [PubMed]

28. Sánchez-Conde, P.; Beltrán-Velasco, A.I.; Clemente-Suárez, V.J. Influence of psychological profile in autonomic response of nursing students in their first hospital clinical stays. Physiol. Behav. 2019, 1, 99-103. [CrossRef]

29. Hayes, S.C.; Strosahl, K.; Wilson, K.G.; Bissett, R.T.; Pistorello, J.; Toarmino, D.; Polusny, M.A.; Dykstra, T.A.; Batten, S.V.; Bergan, J.; et al. Measuring Experiential Avoidance: A Preliminary Test of a Working Model. Psychol. Rec. 2004, 54, 553-578. [CrossRef]

30. Woodruff, S.C.; Glass, C.R.; Arnkoff, D.B.; Crowley, K.J.; Hindman, R.K.; Hirschhorn, E.W. Comparing self-compassion, mindfulness, and psychological inflexibility as predictors of psychological health. Mindfulness 2014, 5, 410-421. [CrossRef]

31. Clemente-Suárez, V.J.; Fuentes-García, J.P.; de la Vega Marcos, R.; Martínez Patiño, M.J. Modulators of the Personal and Professional Threat Perception of Olympic Athletes in the Actual COVID-19 Crisis. Front. Psychol. 2020, 11, 1985. [CrossRef]

32. Hoffart, A.; Johnson, S.U.; Ebrahimi, O.V. Loneliness and Social Distancing During the COVID-19 Pandemic: Risk Factors and Associations with Psychopathology. Front. Psychiatry 2020, 11, 589127. [CrossRef] [PubMed]

33. Rokach, A. The effect of gender and culture on loneliness: A mini review. Emerg. Sci. J. 2018, 2, 59-64. [CrossRef]

34. Borys, S.; Perlman, D. Gender Differences in Loneliness. Personal. Soc. Psychol. Bull. 1985, 11, 63-74. [CrossRef]

35. Matthews, T.; Danese, A.; Gregory, A.M. Sleeping with one eye open: Loneliness and sleep quality in young adults. Psychol. Med. 2017, 47, 2177-2186. [CrossRef] [PubMed]

36. Griffin, S.C.; Williams, A.B.; Ravyts, S.G.; Mladen, S.N.; Rybarczyk, B.D. Loneliness and sleep: A systematic review and meta-analysis. Health Psychol. Open 2020, 7, 2055102920913235. [CrossRef] [PubMed]

37. Qualter, P.; Brown, S.L.; Rotenberg, K.J. Trajectories of loneliness during childhood and adolescence: Predictorsand health outcomes. J. Adolesc. 2013, 36, 1283-1293. [CrossRef]

38. Curcio, G.; Ferrara, M.; De Gennaro, L. Sleep loss, learning capacity and academic performance. Sleep Med. Rev. 2006, 10, 323-337. [CrossRef]

39. Douglas, P.K.; Douglas, D.B.; Harrigan, D.C.; Douglas, K.M. Preparing for pandemic influenza and its aftermath: Mental health issues considered. Int. J. Emerg. Ment. Health 2009, 11, 137-144.

40. Csibi, S.; Griffiths, M.D.; Demetrovics, Z.; Szabo, A. Analysis of Problematic Smartphone Use Across Different Age Groups within the 'Components Model of Addiction'. Int. J. Ment. Health Addict. 2021, 19, 616-631. [CrossRef]

41. Bonetti, L.; Campbell, M.A.; Gilmore, L. The relationship of loneliness and social anxiety with children's and adolescents' online communication. Cyberpsychol. Behav. Soc. Netw. 2010, 13, 279-285. [CrossRef]

42. O'Reilly, M. Social media and adolescent mental health: The good, the bad and the ugly. J. Ment. Health 2020, 29, 200-206. [CrossRef]

43. Nathan DeWall, C.; Pond, R.S., Jr. Loneliness and smoking: The costs of the desire to reconnect. Self-Identity 2011, 10, 375-385. [CrossRef]

44. Sember, V.; Jurak, G.; Kovač, M.; Đurić, S.; Starc, G. Decline of physical activity in early adolescence: A 3-year cohort study. PLoS ONE 2020, 15, e0229305. [CrossRef] [PubMed]

45. Hawkley, L.C.; Thisted, R.A.; Cacioppo, J.T. Loneliness predicts reduced physical activity: Cross-sectional \& longitudinal analyses. Health Psychol. 2009, 28, 354-363. [PubMed]

46. Laursen, B.; Hartl, A.C. Understanding loneliness during adolescence: Developmental changes that increase the risk of perceived social isolation. J. Adolesc. 2013, 36, 1261-1268. [CrossRef]

47. Lasgaard, M.; Goossens, L.; Elklit, A. Loneliness, depressive symptomatology, and suicide ideation in adolescence: Cross-sectional and longitudinal analyses. J. Abnorm. Child Psychol. 2011, 39, 137-150. [CrossRef] [PubMed] 
48. Martínez-González, M.B.; Turizo-Palencia, Y.; Arenas-Rivera, C.; Acuña-Rodríguez, M.; Gómez-López, Y.; Clemente-Suárez, V.J Gender, Anxiety, and Legitimation of Violence in Adolescents Facing Simulated Physical Aggression at School. Brain Sci. 2021, 11, 458. [CrossRef]

49. Martínez-González, M.B.; Arenas-Rivera, C.P.; Cardozo-Rusinque, A.A.; Morales-Cuadro, A.R.; Acuña-Rodríguez, M.; TurizoPalencia, Y.; Clemente-Suárez, V.J. Psychological and Gender Differences in a Simulated Cheating Coercion Situation at School. Soc. Sci. 2021, 10, 265. [CrossRef]

50. Martínez-González, M.B.; Pérez-Pedraza, D.C.; Alfaro-Álvarez, J.; Reyes-Cervantes, C.; González-Malabet, M.; Clemente-Suárez, V.J. Women Facing Psychological Abuse: How Do They Respond to Maternal Identity Humiliation and Body Shaming? Int. J. Environ. Res. Public Health 2021, 18, 6627. [CrossRef] [PubMed]

51. Clemente-Suárez, V.J.; Ramos-Campo, D.J.; Mielgo-Ayuso, J.; Dalamitros, A.A.; Nikolaidis, P.A.; Hormeño-Holgado, A.; TorneroAguilera, J.F. Nutrition in the Actual COVID-19 Pandemic. A Narrative Review. Nutrients 2021, 13, 1924. [CrossRef]

52. Clemente-Suárez, V.J.; Martínez-González, M.B.; Benitez-Agudelo, J.C.; Navarro-Jiménez, E.; Beltran-Velasco, A.I.; Ruisoto, P.; Diaz Arroyo, E.; Laborde-Cárdenas, C.C.; Tornero-Aguilera, J.F. The Impact of the COVID-19 Pandemic on Mental Disorders. A Critical Review. Int. J. Environ. Res. Public Health 2021, 18, 10041. [CrossRef] [PubMed]

53. Clemente-Suárez, V.J.; Dalamitros, A.A.; Beltran-Velasco, A.I.; Mielgo-Ayuso, J.; Tornero-Aguilera, J.F. Social and psychophysiological consequences of the COVID-19 pandemic: An extensive literature review. Front. Psychol. 2020, 11, 3077. [CrossRef]

54. Clemente-Suárez, V.J.; Navarro-Jiménez, E.; Moreno-Luna, L.; Saavedra-Serrano, M.C.; Jimenez, M.; Simón, J.A.; Tornero-Aguilera, J.F. The Impact of the COVID-19 Pandemic on Social, Health, and Economy. Sustainability 2021, 13, 6314. [CrossRef]

55. Martín-Rodríguez, A.; Tornero-Aguilera, J.F.; López-Pérez, P.J.; Clemente-Suárez, V.J. Gender Differences in Nutritional, Odontological and Psychological Patterns of Adolescent Students during COVID-19 Pandemic. Appl. Sci. 2021, 11, 8499. [CrossRef] 